\title{
Benefactor or Burden: Exploring the professional identity of safety professionals
}

\author{
David J. Provan ${ }^{1,2}$, \\ Sidney W. A. Dekker ${ }^{1}$, \\ Andrew J. Rae ${ }^{1}$ \\ ${ }^{1}$ School of Humanities, Griffith University, 170 Kessels Road, QLD 4111, Australia. \\ ${ }^{2}$ Corresponding author e-mail address: david.provan@griffithuni.edu.au
}

\begin{abstract}
The professional identity of safety professionals is rife with unresolved contradictions and tensions. Are they advisor or instructor, native or independent, enforcer of rules or facilitator of front-line agency, and ultimately, a benefactor for safety or an organizational burden? Perhaps they believe that they are all of these. This study investigated professional identity through understanding what safety professionals believe about safety, their role within organizations and their professional selves. Understanding the professional identity of safety professionals provides an important foundation for exploring their professional practice, and by extension, understanding organizational safety more broadly. An embedded researcher interviewed 13 senior safety professionals within a single large organization. Data was analyzed using grounded theory methodology. The findings were related to a five-element professional identity model consisting of experiences, attributes, motives, beliefs and values, and revealed deep tensions and contradictions. This research has implications for safety professionals, safety professional associations, safety educators, and organizations.
\end{abstract}

Keywords: safety professional, safety, professional identity, institutional work, institutional logics, organizational paradox

\section{Citation:}

Provan, D.J., et al., Benefactor or burden: Exploring the professional identity of safety professionals, Journal of Safety Research (2018) https://doi.org/10.1016/j.jsr.2018.05.005

Received 19 November 2017, revised 12 February 2018, accepted 8 May 2018 


\section{Introduction}

The safety profession has evolved significantly over the past 30 years. Increasing safety regulation and social expectation for safety, has expanded the size and seniority of the profession within organizations and across industry. However, we have a limited understanding of their current role and practice within organizations (Provan et al. 2017). We understand even less about who they are and what they believe about safety - their professional identity. To embrace, work with, and make changes to the safety profession, it is paramount we understand how they view their world.

There are existing stereotypes associated with the safety profession, such as: Policeman (Walters 1999), Bureaucrat (Woods 2006), Priest (Dekker 2018) and Psychologist (Walters 1999). These are outsider perceptions of the safety profession, not models of professional identity. They are portrayals of who others think safety professionals are, not who safety professionals think they are. There is no existing research into the professional identity of safety professionals.

This research aims to understand the safety professional in a more intimate way than previous descriptive research into their tasks and education. Beyond the organizational focus on translating knowledge ('knowing') to practice ('doing'), professional identity looks at the combination of these with other aspects of the individual to understand who they are ('being') (Snook et al. 2011). Understanding professional identity is pivotal for understanding how professionals embed themselves in organizations (Webb 2015). However, there has been limited research into professional identity broadly across the professions (Clarke et al. 2013).

Professional identity helps us to understand why professional practice is the way that it is, therefore providing the potential for change and improved effectiveness, that may, in the case of safety professionals, lead to safer organizations. This type of study, to understand the recursive relationship between professional identity and the identity of a profession, has been called for in the literature (Hotho 2008). The findings describe a view of safety professional identity. Because professional identity is self-described, the findings make no inferences about effectiveness or ineffectiveness of safety professionals, nor do they judge whether safety professionals' selfconcept and beliefs are good or bad.

\subsection{The Safety Profession}

The professional identity of safety professionals is situated within the context of their organization, and their profession more broadly. This is the intersection between who they are and the context in which they perform their role. The Safety Profession in its present form is approximately 30 years old and to a large extent remains immature and fragmented. Provan et al. 
(2017) conducted a comprehensive literature review on the role shaping factors of safety professionals across organizational, social and individual dimensions. 25 factors were identified, for example: legal regulation, education, professional accreditation, safety culture, job design, and senior management. Despite the significant recent efforts of the International Network of Safety and Health Practitioner Organizations (INSPHO) to define, standardize, train and accredit safety professionals, the experiences of working safety professionals vary considerably across organizations, industries and nationalities (Pryor et al. 2015).

The present role of safety professionals within organizations has been the subject of significant research. The tasks and activities, education and practice of safety professionals across many countries has been described in the existing literature. Hale and Guldenmund (2006) surveyed more than 8000 safety professionals in over 12 countries to determine the core and common tasks and activities of safety professionals. Chang et al. (2012) surveyed almost 300 safety professionals and safety educators to establish the core competencies and curricula for the education of safety professionals. Daudigeos (2013) observed safety professionals enacting practical agency and proposed the mechanisms through which they influence safety in organizations. The safety professional body of literature, represented in the examples above, provides a description of what safety professionals might do in organizations and how they are educated. The gap in the existing safety professional literature, is research into how safety professionals think and feel about, and identify with their role. This case study into the professional identity of safety professionals begins to address that gap.

\subsection{Professional Identity}

Professional identity refers to an individual's self-concept about their professional role based on their experiences, attributes, motives, beliefs, and values (Ibarra 1999). This is distinct from their organizational identity which is an indicator of an individual's personal association with where they presently work (Pratt et al. 2006). Professional identity has been scantly researched over the past 40 years, and generally only in respect of long-established professional disciplines e.g. education (e.g. Beijaard et al. 2004; Clarke et al. 2013; O’Connor 2008), and healthcare (e.g. Benoit 1994; Chromik 2015; Pratt et al. 2006).

Professional identity is a complex individual phenomenon that is shaped by both individual and contextual factors surrounding their professional life (Clarke et al. 2013). Individuals continually bridge their personal identity with their professional identity through participation, observation, interpretation, and re-interpretation of individual and organizational experiences (Beijaard et al. 2004). Thus, professional identity is both an individual and a social construct shaped by education, moral, and conceptual frameworks and also by the performance of 
roles strongly determined by the professional community and organization (Bévort and Suddaby 2016; Giddens 1984; Hotho 2008; Kogan 2000). Individuals develop and adjust their identity as they acquire discourses (Gee et al. 1996) from many knowledge sources, such as: affect, human relations and subject matter (Beijaard et al. 2004). Professional identity is both a product of structure and a product of choice (Bourdieu 1993; Hotho 2008).

\subsection{Investigating professional identity}

Given the constructivist nature of the development and interpretation of professional identity, much of the research into professional identity consists of context specific qualitative case studies (Pratt et al. 2006). Professional identity research needs to consider the personal and often unconscious nature of the beliefs associated with professional identity. The aspects of individual and social life that form professional identity are tacit and unarticulated and significantly influenced by family, close relationships, early career experience, and professional traditions (Sugrue 1997). Individuals internalize these professional and social experiences mostly without giving them much critical reflection (Clarke et al. 2013). Therefore, professional identity research needs to find ways to elicit these underlying individual narratives through observation and open discussion with professionals, concerning themselves, their subject matter, and their role (Webb 2015). Qualitative case studies provide researchers with the opportunity to explore professional identity as a complex social and individual phenomenon.

Sugrue (1997) developed a theory of the formation of professional identity of teachers through analyzing interview transcripts of 9 student teachers for emerging themes. Gibson et al. (2010) conducted 2 focus groups of student counsellors at a single academic institution, using qualitative research methods and grounded theory analysis to develop a professional identity theory of new counselors. Kosmala and Herrbach (2006) conducted semi-structured interviews with 18 practicing financial auditors and 10 former auditors in the UK and France to establish a theory of professional identity in audit firms. Eliot and Turns (2011) conducted a study on the formation of professional identity among engineering students through conducting 4 workshops with a total of 36 participants from a single institution, where participants completed an online survey consisting of open-ended questions. Williams (2010) completed one hour semi-structured interviews with 15 participants to explore the creation of new professional identities for participants who had undergone a career change into the teaching profession. O'Connor (2008) conducted semi structured interviews with 3 participants to establish discourses of emotionality and professional identity through the lived experience of teachers. The small number of participants in each of these studies is a reflection of the depth required in each individual case (participant) when exploring professional identity. Case study research should be depth-first 
rather than breadth-first research and where a single case may comprise an entire study (Yin 2017).

Professional identity forms and evolves at the intersection of the individual and their landscape. As professional identity is constantly evolving, it will be influenced by the context that the professional is currently operating within including their current organization (Beijaard et al. 2004; Reynolds 1996). Tensions between agency (the personal dimension) and structure (the socially given) manifest in descriptions of professional identity (Coldron and Smith 1999). Researchers need to find ways through their sampling and data collection to isolate professional identity from organizational identity. In this way researchers are able to describe the thoughts, beliefs and actions of professionals, as they are derived from the individual, historical, structural and social landscapes.

The position of the researcher relative to the research (reflexivity) is particularly important for professional identity analysis. The implicit professional identity of participants is made explicit through an ongoing dialogue and discovery between participant and researcher (Gibson et al. 2010). For this reason, it is common to include in the research team a member of the profession under investigation.

\section{Methods}

\subsection{Participants}

13 senior safety professionals from an Australian Energy Company participated in this study. As professional identity is both an individual and a social construct (Kogan 2000) participants were deliberately selected from within a single organization (social system). This research design enabled the separation of individual identity constructs from those related to organizational identity. These participants were performing a diverse mix of dedicated generalist and technical specialist safety roles. Participants are currently mid-level and senior-level safety professionals and all were recruited into the organization to perform safety professional roles, i.e. no participants had performed other roles in the organization prior to their appointment as a safety professional. 12 participants were male, and 1 participant was female. Participants had worked in full-time safety professional roles for between 2 and 20 years with an average of 11 years of experience. 8 of the 13 participants had tertiary safety qualifications. 


\subsection{Procedure}

Each participant took part in a semi-structured interview completed by the first author. The first author has been a safety professional for 18 years, has undergraduate and postgraduate safety qualifications, and is the most senior safety professional within the participants' organization. The duration of the professional relationship between the embedded researcher and the participants range from 1 to 16 years. The embedded researcher's 18 years of personal experience in safety professional roles and more than six years within the organization enabled a deep empathy and trust with participants.

Professional identity is largely tacit to an individual (Wackerhausen 2009) and is, therefore, best understood by asking about their experiences, attachments and beliefs, rather than directly asking how they see their professional identity (Barbour and Lammers 2015). There were four open-ended questions asked during the interview:

1. Describe your safety background.

2. Describe how you think safety is best managed in organizations.

3. Describe your role as a safety professional in the organization.

4. Describe your major successes in your career as a safety professional.

Interviews were conducted in December 2016. All interviews were audio-recorded, resulting in 655 minutes of audio and 169 pages of transcripts.

\subsection{Analysis}

The interview data was analyzed using a progressive comparison grounded theory method (Corbin and Strauss 2014) to thematically analyze the content of what was said, and discourse analysis techniques were further used to analyze how it was said (i.e. links and omissions, language, linked concepts, qualifiers and uncertainty, category distinction) (Creswell 2014).

A collaborative analysis process was used where members of the research team individually completed an analysis, and then together each transcript and the proposed themes were discussed, compared and refined (e.g. Feldman 2004). Themes were continually weighted as more participants independently referred to them. A threshold was set for themes to become findings of the research when 10 of the 13 participants made a strong reference to the theme. Following the analysis, a five element professional identity model (Ibarra 1999; Schein 1978) was selected to classify and report the findings. In text quotations are identified with each participants reference number in square brackets [1-13]. 


\section{Results}

Safety professional identity is shaped by an individual's: experiences, attributes, beliefs, motives, and values (Ibarra 1999; Schein 1978). Each of these elements combines and recombines through practice to determine an individual's self-concept of their role as a safety professional. The analysis identified eight findings which were later categorized in relation to these five elements of professional identity (see table 1).

Table 1: Safety professional findings by element of professional identity

\begin{tabular}{ccc}
\hline Element & Finding & \\
\hline Experiences & 3.1 .1 & Career pathway is the dominant factor in determining safety professional identity \\
\hline Attributes & 3.2 .1 & Relationships are more important than authority \\
\hline Beliefs & 3.2 .2 & Interpersonal skills are more important than technical skills \\
\hline Motives & 3.3 .1 & Safety improves by enabling change in organizations and people \\
\hline Values & 3.4 .1 & Modern safety bureaucracy is an encumbrance on safety \\
\hline 3.5 .1 & Leadership is accountable for safety \\
\hline
\end{tabular}

The number of references to individual findings across the interviews ranged from 80 references to bureaucracy (3.3.2) to 11 references to moral motivation (3.4.1) (see table 2).

Table 2: Participant references to safety professional findings

\begin{tabular}{|c|c|c|c|}
\hline Finding & & Participants & References \\
\hline 3.1 .1 & Career pathway is the dominant factor in determining safety professional identity & 12 & 45 \\
\hline 3.2 .1 & Relationships are more important than authority & 10 & 29 \\
\hline 3.2 .2 & Interpersonal skills are more important than technical skills & 10 & 25 \\
\hline 3.3 .1 & Safety improves by enabling change in organizations and people & 10 & 42 \\
\hline 3.3 .2 & Modern safety bureaucracy is an encumbrance on safety & 13 & 80 \\
\hline 3.4 .1 & Safety Professionals have a moral and ethical motivation for safety & 10 & 11 \\
\hline 3.5 .1 & Leadership is accountable for safety & 13 & 38 \\
\hline 3.5 .2 & Safety Professionals make decisions about what is safe and unsafe & 11 & 44 \\
\hline
\end{tabular}


Detailed analysis of the above themes revealed deep tensions and contradictions associated with participants safety professional identity that appear un-consciously unresolved (see table 3).

Table 3: Tensions and contradictions associated with safety professional identity

\begin{tabular}{|c|c|c|}
\hline Finding & & Tensions \& Contradictions \\
\hline 3.1 .1 & $\begin{array}{l}\text { Career pathway is the dominant factor in } \\
\text { determining safety professional identity }\end{array}$ & $\begin{array}{l}\text { Operational experience vs. Academic education } \\
\text { (Value diversity but undervalue experiences different to their own) }\end{array}$ \\
\hline 3.2 .1 & Relationships are more important than authority & $\begin{array}{l}\text { Relational influence vs. Formal authority } \\
\text { (Value belonging but require authority) }\end{array}$ \\
\hline 3.2 .2 & $\begin{array}{l}\text { Interpersonal skills are more important than } \\
\text { technical skills }\end{array}$ & $\begin{array}{l}\text { Interpersonal skills vs. Technical knowledge } \\
\text { (Value interpersonal skills but are valued for their technical knowledge) }\end{array}$ \\
\hline 3.3 .1 & $\begin{array}{l}\text { Safety improves by enabling change in } \\
\text { organizations and people }\end{array}$ & $\begin{array}{l}\text { Enabling change vs. Protecting operations } \\
\text { (Value change but undervalue the protection of existing operations) }\end{array}$ \\
\hline 3.3 .2 & $\begin{array}{l}\text { Modern safety bureaucracy is an encumbrance } \\
\text { on safety }\end{array}$ & $\begin{array}{l}\text { Bureaucracy vs. Agency } \\
\text { (Value freedom but believe safety requires bureaucracy) }\end{array}$ \\
\hline 3.4 .1 & $\begin{array}{l}\text { Safety Professionals have a moral and ethical } \\
\text { motivation for safety }\end{array}$ & $\begin{array}{l}\text { Moral safety professionals vs. Un-ethical organizations } \\
\text { (Value morals and ethics but believe others don't) }\end{array}$ \\
\hline 3.5 .1 & Leadership is accountable for safety & $\begin{array}{l}\text { Alignment with line-management vs. Independence advice } \\
\text { (Value leadership accountability but believe they don't understand safety) }\end{array}$ \\
\hline 3.5 .2 & $\begin{array}{l}\text { Safety Professionals make decisions about what } \\
\text { is safe and unsafe }\end{array}$ & $\begin{array}{l}\text { Drawing-the-line for safety vs. Others making operational decisions } \\
\text { (Value control but respect others authority to make decisions) }\end{array}$ \\
\hline
\end{tabular}

\subsection{Experiences}

Experiences are described as events or occurrences, which leave an impression on the safety professional regarding how they think about and practice their role. A safety professional's background can be described in terms of their education, workplace experiences and more broadly, life experiences.

\subsubsection{Operational experience vs. Academic education}

The most common and distinct aspects of a safety professionals career experiences relevant to how they think about safety and their role is their formal academic safety education and, or, experience in high-hazard frontline operations. These primary career pathways into the 
safety profession determine an individual's safety understanding, empathy for frontline work, and what they believe creates safety in the organization.

'different individuals through education, through their own experiences, their own backgrounds in different organizations will approach safety differently.' [13]

Safety professionals entering the safety profession through tertiary safety education prior to identifying as a safety professional creates a belief that they 'know' how to create safety. Safety professionals that went into their academic safety education without front-line work experience had little practical insight into what the safety profession did.

'Back then it was, well, what does a Health and Safety person do? And all I got most of the time from my dad, he's a diesel mechanic, and all he sort of said was, "Well, I think they just walk around with a clipboard and tell you whether something's right or wrong, or safe or unsafe.' [6]

After several years of work as a safety professional, they realize that their tertiary education has very little relevance to performing their role effectively.

'I didn't get any specific safety training [in my degree] that I'd consider valuable; most of it was learning on the job' [10]

Safety professionals that have front-line operational experience in high hazard roles or more broad work experience before entering the safety profession believe that tertiary safety education is not the most important experience. Further, they criticize safety professionals that approach their roles from an academic, rather than practical perspective.

'they need to design the elegant system to meet those requirements, and they need to draw the line in the sand and hold to those requirements. So, I think there's a group of people that are very theoretical in their approach to safety and very rigid around safety and I kind of think that's personally disappointing' [11]

'there's a blind deference to the systems that support them, that they see as the crutch for them to walk with and it provides them an opportunity to speak to something that they think is in their technical remit and that is the safety management system.' [2]

Some safety professionals don't have any formal safety qualifications.

'So that's my career ... essentially 20 odd years of experience. But no formal qualifications though' [4] 
As is common in the safety profession, several participants had commenced the first part of their career in safety-critical operational roles and then transitioned to a career as a safety professional. This career pathway led to more discussion and empathy for creating safety at the front-line of the organization and more inclusive and collaborative approaches to their role.

'So, my trade and paramedic background give me the people interface and understanding ability, so to go, how do you take a concept from, say, corporate or a standard and then how does that actually look at the person on the ground, how would they interface with that and how would it be effective?' [3]

Some participants had both an operational career background as well as subsequent tertiary safety qualification. When asked directly which of these experiences they draw on the most to be effective in their role, all of them said their operational experience.

'what's helped me build that rapport, build those relationships is that ... high-risk background ... I can actually understand or see from previous [operational experience] ... what the actual risk is, so I've got that practical understanding ... I'm unsure if I just had the academics, I'd be as successful or if I'd be able to build those relationships' [13] 'more from my time on the tools, my practical experience that I learnt. Uni was definitely important ... But I think the ability to be able to approach a conversation and to also understand that ... people do take shortcuts and try and understand well why do we actually do that? Why are we skipping six, seven? Is there actually a better way to do things?' [12]

Participants with academic safety backgrounds believe that tertiary education should be a pre-requisite for all safety professionals and without tertiary qualifications, safety professionals are not effective

'We shouldn't be employing people without tertiary quals in the health and safety role' [1]

'they have something like 11 safety people in the field, eight of which have almost no qualifications. So again, you're going what do you really, you know what's the point? You're actually not even adding value, you're de-valuing the whole profession to a large extent ... they're lollipop distributors, that's their job, then I'd just go get rid of them. Have four or five really good ones, not 11 shit ones.' [5] 
Conversely, participants without academic safety qualifications and instead many years of frontline operational experience believe that there should be a much broader focus on organizations selection requirements for safety professionals.

'I would be overlooked for somebody with a more robust safety resume. So, I think that for me polarizes the conversation around safety. So, what we're, what we first do is look at the academic attributes of the individual and we look past the nontechnical skills that those people may have and we go through a very burrowing processing to short list some candidates that we're then going to, put in front of a selection panel of senior leaders who may have a little understanding of what operational safety means, to then have an output that is the employment of an individual in a position that they're ill-equipped for. And we go through and make the mistake time and time again.' [2]

This tension between tertiary qualified safety professionals and those with high-hazard operational experience in front-line roles leads to some participants without tertiary safety qualification not referring to themselves as safety professionals even though they are performing that role.

'that for me was my first full-time safety role within an organization ... it actually quite challenged me around how safety professionals view safety.' [2]

All safety professionals agree that tertiary qualifications on their own are not enough and that current academic education does not sufficiently prepare safety professionals to be effective in their roles.

'where our education system falls over is we embed a lot of, you know, academics and professionals within our institutions that, that are teaching what they think should be taught. They haven't necessarily had the opportunity to walk in the shoes of the people for whom they think that they're protecting to be able to craft an understanding of what actually ... creates and benefits safety or how does an organization view safety.' [2]

'You know you want your safety manager to be a professional safety person but what is the right qualification and then, and it can't just be qualification only, it's got to be matched to something else ... we need to match with the right experience and the right personal qualities as well.' [11]

Safety professionals with part of their working lives spent outside the safety profession believe that this time makes them a more effective safety professional, even if that means leaving the profession and then returning. 
'I just think for safety professionals it's I think actually important to, to move out of the safety field if your, you know if your own organization can't do it for you then I think you need to do it because you'll actually end up being a lot better safety professional.' [11]

The professionalization of the safety profession has occurred over the past 20 years, and many participants have witnessed this entire development through their working lives.

'it was only in 1995 was the first time we actually, they employed, at a site with over 300 people full time ... a professional safety person, so someone whose background was safety' [11]

The vastly different work and education experiences of safety professionals combine with a confused role expectation in modern organizations (Provan et al. 2017). Perhaps, the safety profession hasn't yet found its place or role in their organization.

'we don't clearly define what we want a safety professional to do. We don't really clearly empower them. So, they're kind of in this amorphous zone, and it's just really hard work'

Safety professionals describe their career experiences and relate these to how they think about safety and their role within organizations. Those that have academic backgrounds in safety, particularly early in their working lives talk to the development of technical skills and their usefulness in providing advice in their role. Those that have extensive experience in front-line operational roles talk to their understanding and experience of how work gets done and their ability to relate to those at the front-line of the organization. Most interestingly, alongside the individual belief that their career pathway is the most effective, they actively discredit and devalue those safety professionals with different career pathways and experiences. Safety professionals do not value the diversity of career experience in the safety profession, but rather believe there is one best background for an effective safety professional that aligns with their own.

\subsection{Attributes}

Attributes are described as a quality or feature that can be regarded as a characteristic or inherent feature of a safety professional. Professional attributes commonly described in the safety professional literature are technical skills and interpersonal skills. Safety Professionals believe that both technical skills and interpersonal skills are important for them to be effective in their role, however, conclude that interpersonal skills are the most important. Consistent with the bias towards the importance of interpersonal skills, safety professionals believe that relationships are more important than having authority. Safety professionals believe they are most effective in 
their role when they can use their interpersonal skills and relationships to influence others, rather than when they can use their technical skills and formal organizational authority to control others.

\subsubsection{Relational influence vs. Formal authority}

Safety professionals universally describe the importance of line managers within their organization leading and owning safety. Safety professionals see their role as supporting and enabling line managers. To do this effectively, they describe the importance of relationships with others in the organization, and through this the ability to influence their decisions and actions.

I see my role as a partner and a support and enabler to the organization to deliver a great safety outcome, but also to deliver a great business outcome’ [4]

Although safety professionals see themselves as a partner to line managers and others in the organization and they value relationships over authority - many others in the organization have a different perspective.

I would always in passing hear about a meeting because no one else was at their desks.

So, the structural guys aren't there, mechanical guys aren't there, piping isn't there, project managers aren't there - safety are all sitting in their cubical ... and we're thinking we're making this place safer, but little did we know, upstairs the whole entire design team, except safety, are sitting there making decisions that are contrary to the documents we're writing.' [10]

Safety professionals consider it important to have alignment, and agreement, on their role, the role of line managers and the interface between them.

'work some alignment around whatever [management] think their role is today versus what I think it should be ... and try and just to get some alignment so that we're actually moving in concert' [7]

Safety professionals understand the Importance of relationships to understand the perspectives of others and to be involved in the business.

'For me, you've got plant and field managers and those guys in charge of people and they get pressures from production, they get pressures from safety, they get pressures from a whole suite of areas so you've really got to kind of just let them talk and understand' [1]

I personally get a huge amount of value when I go to the field, talk to some of the guys on the ground. I feel I can do it in a non-threatening manner and then I can help' [5] 
'a lot of it is really getting involved with what I would call the DNA of how the site actually works, as being an integral part of that.' [6]

Safety professionals aim to influence safety by working 'through' others throughout the organization and to do this they invest heavily in developing effective relationships.

'I spend a lot of time influencing people and managing relationships, and making sure that we've got an in-road into the business that's, that is in a real partnership way, so that were, embedded and entrenched into the organization. So, I spend a lot of time on relationships' [4]

'as safety professionals move through their careers, it's the ability to influence down, but you've also got to have the ability to influence up as well and across. ' [12]

'I used to be arrogant enough to think that as a one man I could make a difference on the ground, and the reality is, is that I can only do that if I can work through others. But I can't actually do it on my own.' [7]

Safety professionals do not believe that using the formal or informal authority vested in their role is an effective way to steer safety and they understand the negative impact that leveraging authority can have on peer relationships.

I'm pragmatic; I'm not just a dude wielding an HSEMS, slamming it down on tables every now and again, or evangelizing.' [10]

'[Using authority] that's where we don't add value because we mess that up and we lose that relationship, that credibility, that trust straight away' [13]

Safety professionals do not have any 'real' safety authority anyway. Although they have the responsibility to make decisions about, say, the content of a safety document, they do not make any operational decisions that directly impact safety outcomes.

'it's not my business unit so I'm not going to make the decision, but I'm going to provide a compelling argument one way or another' [9]

'the first thing that struck me ... was the actual challenge of that [safety professional] role and how hard that role actually is because you actually don't have any direct line management ownership. So, you've got a huge interest and a huge care and concern, but you actually don't own anything. So, it moves from a, for myself personally from where I could very much take control, make decisions and actually make things happen, to where I'm, you know, coaching, mentoring, prodding where it needs to be.' [11] 


\subsubsection{Interpersonal skills vs. Technical knowledge}

Safety professionals believe that while a baseline of technical skills is necessary for them in their role, it's their interpersonal skills that determine their effectiveness. It's these interpersonal skills that assist them in developing the relationships described above.

'how they can just interact with people and build relationships is huge ... and it's actually bigger than the technical aspect. Cos, I can go get a consultant to tell me anything, quite frankly. And to a large extent, I do because businesses tend to believe an external voice more than they do their internal voice. Even if it's exactly the same message. But how you build those relationships and that trust over time is more important than your technical skill set.' [5]

Safety professionals describe the following interpersonal skills as necessary: communication, collaboration, listening, facilitation and coaching.

'a lot of people cannot communicate well enough to - especially in operations - get things done' [1]

'if you see something coming, how do you raise that with a manager or management team without saying the sky's falling.' [5]

'Enabling for me is also about trying to collaborate with the business, so I think that comes back to this sort of notion of do stuff with the business, not to the business. ' [8] 'open up the communication line, instead of driving a message from the corporate down we needed to get a message from the field up. So, they needed to tell us what was important' [9]

'I see my role as a facilitator, and through facilitation, I provide both service and governance' [10]

'Probably in a future state you probably don't even need a safety professional, you probably just need someone who knows how to engage with individuals and talk through and coach them on how your organizational culture should be.' [6]

Safety professionals describe their need to relate to others, have emotional intelligence, be credible, open and honest and generally be a 'people-person'. 
'I truly believe successful people within the safety function they need to be people-people ... They need to be able to communicate and relate to our people within the business, no matter what function' [13]

'emotional intelligence, you know, understanding the dynamics and the pressures that the different people you're trying to influence are under-you can't be a bull in a china shop; you'll just fail.' [1]

'Yeah, and it's really just being open and honest and not getting too emotional' [1]

'it sounds a bit weird, but I guess just being - this is going to sound really weird - being a normal person, quite frankly' [5]

Safety professionals downplayed the importance and usefulness of technical safety skills in their day-to-day professional practice.

'There's no point being a technical boffin all the time when you're not actually making any change to the world or the way people do their stuff, whatever that might be.' [10]

Safety professionals with 'safety technical skills' don't necessarily have the 'work technical skills' associated with the tasks and equipment being used in the organization.

'I haven't been out there before and swung the tools or pressed the buttons on the gas plant, or whatever it is. You know, therefore there is that potential that people go well you've never done this, you've never lived in my shoes before so how the hell would you know' [5]

\subsection{Beliefs}

Beliefs are described as a trust, faith, confidence in, or an acceptance that something exists or is true. Safety professionals believe that safety improves through changing organizations and people and that modern safety bureaucracy is an encumbrance on safety.

\subsubsection{Enabling change vs. Protecting operations}

Safety professionals describe success in their role as enabling change within their organizations. They believe that their organization is not as safe as it needs to be and their role is to lead and enable the necessary change.

'everything I think, most of what I do, is in fact I think is going to make a change.' [10] 'the role of the safety professional is probably more of a change agent' [6] 
Safety professionals create a safety vision for their organizations and enable them to embark on a 'safety journey.'

'I'm leading them through the vision of what great safety could look like three, to five, to ten years' $[4]$

'I've always said that good safety performance and good safety outcomes is a journey, not a destination.' [7]

Safety professionals see their role as enabling safety change and not performing transactional safety work.

'If I can say nothing in that risk assessment and have all of the operational leaders, have the front-line workforce speak to, and be able to contextualize the risks that they're facing that's when I've known I've been successful in my role.' [2]

'I see a lot of [safety professionals] solving it for the business and I kind of think that just further kind of embeds the role of the safety piss boy... being the servant of the business rather than the professor of the business and educating the business.' [11]

Safety professionals describe successful change as improving the capability of the organization and its people to manage safety, i.e., the learning outcomes. Safety professionals do not describe their success in terms of successful work outcomes (i.e., cost and production) or in terms of safety outcomes (i.e., injury rate reduction).

'the success isn't the activity itself, the success is moving the organization to understand why we do this and how it benefits safety.' [2]

Safety professionals describe two areas of change that they enable through their role, programs, and people. Program implementation involves supporting the enhancement of organizational systems and programs.

'the biggest achievement for me there was to help revamp and refresh and revise the whole control of work system and the permit to work system, to the point where I probably trained up about, oh, maybe a couple of hundred people in how to do hazard and risk assessments using risk assessment protocols.' [6]

Building capability in people through coaching and development is the most important aspect of a safety professionals role. 
'I need to be able to build capability through coaching, through mentoring, through experience and exposure and assisting our people to be able to conduct what they do in essence without me in time' [13]

However, building capability in people is an intangible activity for safety professionals and one that they found hard to describe, justify and demonstrate improvements to their organizations.

'the real conflict I have is that that takes time and it's this incredibly busy world and then what's the value you put on, you know, 20 conversations that move the business the right way' [11]

Safety professionals need to make sure that they are implementing the right changes with their organizations - the ones that line managers and front-line workers think needs to be made.

'in the past, we've never really listened. So, we always dictate, never listen' [9]

'we've got to get better at helping the business make the improvements in the areas that they know are weak' [8]

Safety Professionals continuous focus on change and improvement may create tension and instability with existing operations. There is an un-questioned belief that these 'improvements' to people and programs will results in improved safety.

\subsubsection{Bureaucracy vs. Agency}

Institutional factors shape safety professionals understanding of their role, and over time, beliefs about how it is best performed. Safety professionals believe that the modern safety bureaucracy is an encumbrance on their effectiveness in their role. Safety bureaucracy refers to the external regulatory environment as well the procedural controls and safety requirements internal to their organization.

Safety professionals believe that safety bureaucracy including accountabilities, systems, rules, and performance reporting are fundamental to managing safety and their role is fundamental to developing and administering this bureaucracy.

'I actually think systems underpin good safety' [4]

'it's almost fundamental but has to be said ... that we've got the right systems in place that enable compliance' [8]

'they're absolutely fundamental, but they don't need to be overly complicated' [11] 
Safety professionals believe that safety bureaucracy within organizations is overly large and complex, coupled too often with a strict compliance mentality.

'the issues with a lot of systems is that they're very top-heavy and they create a lot of burden, and they tend to get in the way' [6]

'our system underpins everything that we should be doing, but we've overcomplicated everything' [4]

'if someone doesn't have their seatbelt on while they're doing $3 \mathrm{~km} / \mathrm{hr}$... is that something that's going to be a matter of life or death ... there's a whole range of things where I think we've probably over-boiled the ocean a little bit, you know, you can only cross when there's a green man, you can only do this, you can only do that, you know, we've got to have hazard tape around the toaster machine in a corporate office.' [8]

'we've overcomplicated our processes or our systems for our people who use them in the field' [12]

Safety professionals believe that the safety profession has been integral to the development of contemporary safety bureaucracy. Safety professional identity is strongly connected to their role in relation to the elements of safety bureaucracy.

'when you talk to a whole range of safety professionals and industry leaders, and they just say, "We've just taken this stuff too far, right?' [8]

'the blind following of regulation and our compliance mentality that has a negative, I think, effect on the safety outcomes' [2]

Safety professionals describe the burden of safety bureaucracy on them in their role and on the organization more broadly. Further, they describe much of the bureaucratic safety activity as adding no value to safety, particularly safety performance reporting.

'So, the week before was all about preparation of the packs, and then the week after was about the meetings themselves and trying not to get actions out of meetings. So that's literally half my month gone. And I've done zero, apart from hopefully avoiding unnecessary management actions.' [5]

'I sit down thinking, why am I doing this? Is it to give something to somebody that's actually going to add value? Or is it I'm just doing something, and I'm not really sure why I'm doing it, or I'm feeding a machine, I find that quite frustrating if I think I'm just 
feeding an information hungry machine. And we do that a lot I think in our organization, but to no end' [4]

'a lot of time, energy and activity gets done in the name of safety, and most of it's not adding any value, it's just activity' [7]

Safety performance reporting was a specific area of safety bureaucracy that participants continually discussed as burdensome and non-value-added safety activity.

'I still produce quite a lot of data and KPIs and metrics to satisfy boards and people alike that probably at the end of the day don 't add any value to the frontline of safety' [3]

'I think we over-report to a certain extent, and I don't know how much value there is in providing lag report, because it's been and gone, so what use is that to any person really? What's done is done. We've got to get far better at predictable forecasting' [8]

'that might be from senior leaders asking for something that you think, well geez, haven't we supplied that five times?' [4]

'an inordinate amount of time on meetings and reporting that actually don't do anything to actually illustrate what the problems or the performance really is' [7]

Safety bureaucracy, and particularly safety performance reporting is the currency of the relationship between organizational management and the safety professional. Due to the current safety bureaucracy in organizations, safety professionals believe that their relationship with, and support of line management suffers.

'the key part of my role that adds no value for safety is the one that should add the most which is, you know, leadership team meetings and those key forums ... the information we provide to those forums is immature and trite' [11]

'the concept that a senior leadership team don't fully appreciate that they could have a fatality tomorrow and there's actually nothing that they've got that they can rely on wholeheartedly to tell them they're not going to have one' [8]

Safety professionals believe that bureaucratic safety activity absorbs valuable safety resources of the organization and detracts from managing the day-to-day risk in the front-line.

'The area I think that drives me around the wall is just the ineffective allocation of resource to risks that are immaterial' [8] 
'if we use the resource pool to do that, then we're actually taking the resource pool away from the real work which is keeping people safe in the field' [4]

'spending as much time as we do measuring the crap that we actually measure is not an effective use of anyone's scarce resources' [7]

'meeting compliance obligations and other performance metrics that we need to achieve about reporting on safety ... I find tedious. I find that it detracts us from engaging more wholesomely with the organization' [2]

'it has to be managed from the field, owned by the field, and managed with a small team that understands the risks and challenges of the day -to-day world' [9]

While participants believe that many bureaucratic safety activities provide little value to safety, they think that others in the organization, particularly management and other safety professionals have a 'false hope' in the fidelity of these activities.

'I also think we're ignorant when we look at how we think a program such as Lifesaving Rules will create safety or protect individuals. It's a false hope.' [2]

'so, you make out a process and ... you've actually never told the people about it then you've just got a piece of paper, you actually don't have any control; you've got smoke and mirrors' [7]

Safety professionals describe the anxiety, disempowerment, and judgment as unintended but real consequences of safety bureaucracy.

'Safety is super challenging. You have a lot of stakeholders. Everybody's very interested in safety performance. Small things, even though we're not supposed to sweat them these days, you do.' [9]

'I say that because I think it created so much work and I think anxiety in the organization' [2]

'you can't make your own decisions about what's getting applied to your business based on your actual business' [9]

'you do hear sometimes that people say, "This is a butt covering exercise" [12] 'what if I get this wrong, you know, and part of me goes well stiff shit I've made the best decision based on the information at the time ... but the way we handle incidents or the 
way we handle performance management never seems to look at it in that light. It always analyses as the armchair quarter-back' [11]

Safety professionals believe that safety bureaucracy has to be significantly reduced, however, are unsure exactly what that looks like, or how to manage the reduction within the organization.

'Obviously there's areas where pragmatically things are a massive burden, and we need to kind of remove those' [1]

'you can't throw the baby out because you need something' [7]

'every conversation I've had to take something away has been 20 times harder than a conversation to buy more or add more' [11]

Safety professionals believe that the generally accepted descriptions of bureaucratic safety activity, project onto them and that the safety profession is perceived as detached from the day-today work, burdensome, focused on the wrong things, not value adding, and provoking emotive responses. Participants didn't identify personally with this as a self-concept but strongly believed that this is the opinion of those outside the safety profession.

\subsection{Motives}

Motives can be described as a person's 'reason for doing something.' In relation to professional identity, this is the reason for participants becoming a safety professional. Participants described a moral and ethical motivation for performing their role as a safety professional.

\subsubsection{Moral safety professionals vs. Un-ethical organizations}

Safety professionals are motivated in their role by performing a function that contributes to - in their minds - preventing the suffering of others resulting from safety incidents. This motivation stems from one, or a combination of family experiences, previous work experiences or life experiences more broadly.

'Dad had been involved in a serious physical workplace injury that had him in hospital for six weeks and nine months' worth of rehab, and then a couple of years later to have a psychological injury ... the implications of that still manifest itself, what, fucking 25 years later. I started to see how, where this practice as a career actually has the ability to make a difference and be in the service of others.' [7] 
'that could be your Mum and Dad ... or that could be your wife or your husband or whoever, so you know, when I think about what influences me in my role and throughout my career.' [2]

'there's ... a kind of person who's really cut out for that kind of service provision. Some would say probably go into the priesthood, but not quite far off is that people who generally care about things other than themselves.' [10]

Safety professionals that have entered the safety profession after some adult years in the workforce have often experienced events during that time that have connected them personally to their current careers and the development of their professional identity. This is most prominent, for safety professionals that have worked in frontline roles in high-hazard environments, for example aviation, chemical manufacturing, military, emergency services, and construction, to name some of the backgrounds of participants in this study.

'you don't have to look very far to see somebody that's either been killed at work or had a serious injury, losing hands, fingers, etcetera' [9]

'I remember some things that I was asked to do when I was 17 years old that I would never ask anybody reporting to me to do' [12]

'In those first couple of years one of our tankers was conducting an exercise, a patrolling tanker, and we lost four people in an engine room fire ... so that's where the interest in safety stemmed from.' [13]

Even for those safety professionals that don't share a personal connection to the human suffering associated with incidents, they associated the professional identity of the safety profession broadly with this characteristic.

'So, I didn't I guess get into it like lots of people have who ... injured themselves or a family member got injured and therefore felt internal passion or desire' [5]

Safety professionals are also motivated by the opportunity in their role, to console the suffering from incidents by understanding how they occurred and create change in their organization to prevent further suffering in the future. We see this prominently in incident management, investigation and reporting.

'It's unfortunate the events occurred but it's kind of like it would be a shame if we actually didn't come to the right root cause, determine what happened, how to address that' [6] 
Safety professionals see this motivation to prevent human suffering from safety incidents as a noble pursuit, amidst in their minds, the capitalist and heartless core of modern organizations.

'the pull of [safety] was sort of noble ...I almost sold my soul, we dare say, to finance, and I was salvaged by this potential to be [a safety professional] - what I considered to be a noble field' [10]

'I guess it was something that just resonated with me on a, like a value, if you're going to spend that time at work how can you do something that might make a difference?' [7]

Safety professionals are strongly motivated by this moral motivation to prevent human suffering through safety incidents within their organizations. They see this as a reason, or even a necessity, to stand at odds with others who they believe have less moral motivation in their roles. This tension relates to the contradiction between safety professionals doing what they believe is right for safety, versus doing what they think the powerful hierarchy in organizations believes is right for business.

'A lot of people comment, "You say no to management an awful lot," and I said, "Yeah, I do. " [laughs] Whether that's a good thing or a bad thing, I don't know' [7]

This moral identity makes the safety profession similar in motive to the more researched caring professions, most notably, nursing (Benoit 1994) and social work (Webb 2015). Safety professionals often identify their work as a 'calling' beyond merely a career or job. Walsh and Gordon (2008) propose that professionals who view their role as a calling are more likely to view their work as a reason for being and their professional identity closely aligns with their overall self-concept. For this reason, safety professionals take organizational safety decisions and outcomes as a personal reflection on themselves not only on the performance of their role.

Safety professional identity and activities are related to their beliefs about safety and others within the organization (Swuste et al. 2014). This moral motivation for their role has significant implications for safety professional practice within organizations. In a study of Safety Professional influence and practical agency, Daudigeos (2013) found that the 'sense of moral duty to others in [safety] professionals' has powerful implications for institutional processes and safety professionals often resort to unscrupulous and Machiavellian tactics in pursuit of their good intentions.

Despite safety professionals motive of preventing suffering, there is no empirical basis that they are delivering on this objective (Borys 2015). This might be somewhat explained by 
safety professionals within organizations designing and implementing 'safety work' rather than improving the 'safety of work' (Rae \& Provan, Manuscript under review).

\subsection{Values}

Values are described as principles, or standards of behavior resulting from one's judgment of what's important in life. Safety professionals believe that leadership is accountable for safety and their role is to influence others, however, paradoxically, they also believe that they are best placed to determine what is safe and unsafe when it comes to decisions about safety.

\subsubsection{Alignment with line-management vs. Independence advice}

Safety professionals overwhelmingly believe that the leadership and line management of an organization is accountable for safety and this principle helps define their role and professional identity. In relation to leadership accountability, they describe: leading from the top, line ownership, listening to the frontline, support for safety professional work, and interaction between line management and safety professionals.

Safety professionals believe that it is important that safety is led from the very top of organizations.

'there has to be senior leadership commitment' [8]

'I think you have to have it owned at the top' [4]

While, safety professionals believe that safety is led from the top of organizations, they understand the reality of work as done on the front-line and its importance to safety.

'So, absolute ownership at the top, but you also have to have the voice from the bottom.

So, if you have one and not the other, I think you're on a path to nowhere, or just having this dictatorial thing happening' [4]

'when your front-line workforce is actually telling you you're probably going to get us killed then you probably should listen' [2]

Throughout organizations from the very top to the front-line, safety professionals are clear that safety is owned by line management

'the view of safety being managed in the line I agree with' [2]

'I have an absolute belief that you can't have good safety unless it's owned in the line ... if the line are not owning things, then you know, anything can happen out there' [4] 
Safety professionals are clear that the accountability for safety in organizations resides with line management and therefore safety is not owned by them in their role.

'all safety professionals should be pushing away from ownership and pushing that back on the line and the line having ownership and accountability ... we need to move away from thinking that the safety professional is the one that actually keeps people safe' [6]

'I'm not a believer that safety's run by safety [professionals]. ' [11]

Safety professionals see their role is to interact with and contribute to supporting line management with this accountability.

'[safety] has to be thoroughly enabled by the safety professionals.' [11]

However, safety professionals believe that they, as a profession, are currently not supporting line managers as effectively as they should, or could be.

'we continue to have conversations about the small stuff, and actually we need to be having conversations about, "How do I know it's not going to go bang and how do it know it's not going to happen tomorrow? "So [not] sitting in leadership team meetings about the three lost-time injuries that we had' [8]

While safety professionals feel like they are not effectively able to support line management, they require line management support for them to perform their work.

'leaders need to proactively support and promote what we're doing' [13]

Ultimately, safety professionals understand that line management accountability for safety includes the authority and responsibility to make safety decisions.

'management retains the prerogative to make the decision, including making bad ones.

That doesn't make them bad people; we all make bad decisions as individuals, but there's responsibility in there ... for me as long as it's not breaking the law, operating outside an organizational authority then you've had the opportunity to contribute and ... it's time to muck in and support.' [7]

\subsubsection{Drawing-the-line for safety vs. Others making operational decisions}

While safety professionals believe that accountability for safety resides with line management, they paradoxically believe that it is their role to draw-the-line on whether something is safe or unsafe. They believe that it is an important part of a safety professionals positional authority to make these determinations for the organization. This role is described as a position of 
last resort when they feel that they are not being listened to and are unable to influence through their relationships and involvement in line management decision making processes.

Safety professionals see their role as providing recommendations for line managers to make the 'right' decisions to improve safety and overall business performance.

'make some recommendations to improve or reduce the risk of people' [10]

'I personally see my role as a coach, someone who's there to support and provide guidance to help the responsible manager or the leader make the appropriate decisions or the right decisions.' [12]

'then you can offer kind of what the, what the minimum or the bottom line position is' [11]

However, if safety professionals believe that the business is not following their advice or they perceive actions that are inconsistent with their beliefs about what is best for safety, then they have the authority and obligation to draw-the-line. There is a constant tension between the accountability of line management for safety and the safety professional as the ultimate judge of right and wrong. For some safety professionals, it seems they believe that they are ultimately accountable for managing safety risk in the organization.

'there's times where you actually have to be the policeman and say, "No, we just can't do that.' $[8]$

'setting standards and pretty much being able to draw a line in the sand' [2]

'We're managing the risk; we're controlling the risk' [13]

Because safety professionals believe they know the appropriate decision to make for safety in any given circumstance, they monitor and confirm that their recommendations have been implemented and followed.

'[we are] the keeper and consciousness of part of the organization ... there's always an element of sort of policing that is involved in our role.' [8]

I'm not thinking that the direction or the advice I'm getting is being followed, I do know that I've got the authority to actually elevate the conversation' [12]

The contradiction between the contrasting beliefs of line management being accountable for safety yet safety professionals drawing-the-line on safety decisions creates confusion, tension, and conflict. 
'I think a lot of safety professionals still struggle with what it means for the line to be accountable for safety. I think what I've seen that people think "Well we want to hold the line accountable, but we're conflicted and confused' [9]

'balance between how many safety people you have, and the perceived power that they have versus the line accountability piece. And the confidence of the line to fill that role, and actually tell the safety guys to get stuffed on certain topics. There's a trust, but there's also a bit of an actually thanks, that's your advice, and you're here to give advice, and I'm not going to take bad advice on this particular day.' [5]

'there's been a few scenarios where there's been massive clashes between people drawing a line in the sand' [1]

Safety professionals draw-the-line about safety with the clear objective in their mind of preventing safety incidents, however, they have an inner uncertainty about whether they are ultimately achieving this objective in practice.

'it's not around keeping people absolutely safe at the end of the day because I'm not standing out there in the middle of the paddock or in the middle of the field supervising someone. That's where the real safety's at' [6]

'So that's always, sort of even in the back of my mind around you know, am I even right here because you know I haven't done it before. So that's the challenging, the hardest partfor me.' [5]

Further, safety professionals begin to question whether safety professionals in support of line management should be making safety decisions at all, and what is the lost role of the frontline workforce in organizational safety.

'I think where we're going wrong as a discipline is swinging the pendulum too far that people can't think for themselves' [8]

'sometimes we forget about the person who has been operating that machine' [4]

Due to the complicated and confused relationship between leadership accountability for safety, safety professionals knowing what is right and their strong sense of moral duty, if the advice of safety professionals is not followed, they display strong emotional responses.

'people who are passionate about it like, and take work really seriously can often end up in a bad space pretty quickly when they're... you know, what they feel is safe and 
appropriate is not taken on board by production managers and field and plant managers' [1]

In addition to making a moral appeal, safety professionals claim authority and coercive power over safety decisions based on their ability to rely on regulatory arguments (Daudigeos 2013; Scott 2008).

\section{Conclusion}

The professional identity of safety professionals is developed throughout their professional lives, however, is significantly shaped by how they enter the profession. They maintain a hybrid worldview made up of 'pre-modern' moral motives and 'modern' objectives to create a perfectible organization. These ideals and objectives combine with an unclear role within their organizations to create a consistent yet confused professional identity. Safety professionals are unsure of their place in the organization and live with tensions and contradictions about organizations, safety, their role, and their professional identity.

Safety professionals see themselves as upholders of justice, making sure the capitalist objectives of the modern corporation don't come at the expense of the safety of those on the frontline. They believe that it is their job to hold management accountable for safety. Safety professionals hold an ideal model of how organizations should be managed and seek though their role to create it.

Although the safety profession in its current form has evolved over the last 30 years (Provan et al. 2017) the tensions concerning 'safety' within organizations have a much longer history. For example, following a number of mining disasters in the United Kingdom, a collection of 'clergy and learned men', named the South Shields Committee, were formed in 1839, to apply 'morals and science' to the safety problem (South Shields Committee 1843). The South Shields Committee (1843) report reveals similar tensions to those described in the findings of this study, for example: 'experience in the darkness of the mine vs enlightenment and the advancing principles of education' (p.61), 'unassisted efforts of individuals vs. supervision of the state' (p.66), 'moral observers vs. immoral organizations' (p.20), 'faults in the system vs. faults of the officers and the men' (p.33), and 'humane and philanthropic suggestions vs. annihilation of the most productive mines of Britain' (p.6). 175 years later, safety, and the safety profession is still searching for its place within for-profit organizations. 


\subsection{Multiple institutional logics and professional paradoxes}

The contradictions and tensions associated with safety professional identity are exacerbated by them being interpreted as 'or' choices, rather than as 'and' propositions. Safety professionals would benefit from exploring these dilemmas through the theory of multiple institutional logics (Besnharov and Smith 2014; Bévort and Suddaby 2016) and the theory of paradox in management science (Schad et al. 2016).

Safety professionals consciously or unconsciously see these tensions and contradictions in competition, rather than as complimentary. For example, in relation to operational experience vs. academic education, safety is a diverse transdisciplinary profession, and safety professionals and safety departments always benefit from as much diversity of background, experience, and education as possible.

The identified tensions are perhaps not resolvable, and instead to thrive and be effective, safety professionals require a 'paradox mindset' (Miron-Spektor et al. 2017). In this regard, Safety professionals might be considered a new form of 'hybrid professionals' that assist others in the organization to make sense of these competing logics (Blomgren and Waks 2015). We suggest that the safety profession is an ideal group to test paradox theories of organizations and professions.

\subsection{Practical implications}

This research highlights three key practical considerations for safety educators, safety professional associations, safety professionals, and organizations.

1. The safety professional role needs to be better defined and more broadly understood

2. Multiple safety professional career pathways need to be maintained

3. Safety bureaucracy needs to be reviewed for scale and purpose across industry

Safety professional role titles, objectives and tasks vary widely across industry. Defining and aligning around a common role of a safety professional would assist all stakeholders to support and interface with the safety profession. Not-with-standing the considerable work done by international safety professional associations, the practicing safety professional role varies significantly (Provan et al. 2017). The safety profession will benefit from maintaining multiple career pathways, and a thorough review of safety academic education is warranted in light of the findings of this research. For example, including field experience in a safety-critical operational role as part of safety academic education may prove to be an effective method of developing greater empathy for frontline work and a practical understanding of safety. Safety professional 
identity is most strongly and continually influenced by experiences performing safety work in organizations which is largely that defined via safety bureaucracies. The scale, complexity and confused purpose of many bureaucratic safety activities creates a negative perception of safety management within organizations as an operational burden, and by extension, safety professionals internalize that perception, and compensate for it, as part of their professional identity.

Based on this study, future research should seek to understand safety professional identity more broadly across the profession. This would allow the development of a consistent 'identity of the profession' archetype, against which academic pathways and work experiences can be aligned in ways that enhance individual safety professional identity, and ultimately support improved organizational safety outcomes. 


\section{References}

Barbour, J. B. and Lammers, J. C. (2015), 'Measuring professional identity: a review of the literature and a multilevel confirmatory factor analysis of professional identity constructs', Journal of Professions and Organization, 2 (1), 38-60.

Beijaard, Douwe, Meijer, Paulien C., and Verloop, Nico (2004), 'Reconsidering research on teachers' professional identity', Teaching and Teacher Education, 20 (2), 107-28.

Benoit, Cecilia (1994), 'Paradigm Conflict in the Sociology of Service Professions: Midwifery as a Case Study', The Canadian Journal of Sociology, 19 (3), 303-29.

Besnharov, Marya. L and Smith, Wendy. K (2014), 'Mulitple Institutional Logics in Organizations: Explaining Theri Varied Nature and Implications', Academy of Management Review, 39 (3), 364-281.

Bévort, Frans and Suddaby, Roy (2016), 'Scripting professional identities: how individuals make sense of contradictory institutional logics', Journal of Professions and Organization, 3 (1), 17-38.

Blomgren, Maria and Waks, Caroline (2015), 'Coping with contradictions: hybrid professionals managing institutional complexity', Journal of Professions and Organization, 2 (1), 78-102.

Borys, D. (2015), 'Do Occupational Health and Safety professionals improve the occupational health and safety performance of an organisation?', Journal of Health \& Safety Research \& Practice, 7 (1), 2-13.

Bourdieu, Pierre (1993), The field of cultural production (Cambridge: Polity).

Chang, S. H., Chen, D. F., and Wu, T. C. (2012), 'Developing a competency model for safety professionals: correlations between competency and safety functions', J Safety Res, 43 (5-6), 33950.

Chromik, Jessica (2015), 'Changing Professionals: Professionals' role in the institutional dynamics of German health care', (University of Köln).

Clarke, Marie, Hyde, Abbey, and Drennan, Jonathan (2013), 'Professional Identity in Higher Education', 7-21. 
Coldron, J. and Smith, R. (1999), 'Active location in teachers' construction of their professional identities', Journal of Curriculum Studies, 31 (6), 711-26.

Committee, South Shields (1843), 'The report of the South Shields committe: Appointed to investigate the causes of accidents in coal mines', (London).

Corbin, Juliet and Strauss, Anselm (2014), Basics of qualitative research: Techniques and procedures for developing grounded theory (Sage publications).

Creswell, John W (2014), Research Design: Qualitative, Quantitative, and Mixed Methods Approaches (4th Edition edn.: Sage Publications).

Daudigeos, Thibault (2013), 'In Their Profession's Service: How Staff Professionals Exert Influence in Their Organization', Journal of Management Studies, 50 (5), 722-49.

Dekker, S. (2018), The Safety Anarchist: Relying on human expertise and innovation, reducing bureaucracy and compliance (New York: Routledge).

Eliot, Matt and Turns, Jennifer (2011), 'Constructing Professional Portfolios: Sense-Making and Professional Identity Development for Engineering Undergraduates', Journal of Engineering Education, 100 (4), 630-54.

Feldman, M. S. (2004), 'Making Sense of Stories: A Rhetorical Approach to Narrative Analysis', Journal of Public Administration Research and Theory, 14 (2), 147-70.

Gee, J. P., Hull, G., and Lanshear, C (1996), The new work order: behind the language of the new capitalism (St Leonards: Allen \& Unwin).

Gibson, Donna M, Dollarhide, Colette T, and Moss, Julie M (2010), 'Professional Identity Development: A Grounded Theory of Transformational Tasks of New Counselors', Counselor Education \& Supervision, 50, 21-38.

Giddens, A (1984), The constitution of society: Outline of the theory of structuration (United States: University of California Press).

Hale, A. R and Guldenmund, F. G (2006), 'Role and tasks of safety professionals: Some results from an international survey', Safety In Action (Melbourne). 
Hotho, Sabine (2008), 'Professional identity - product of structure, product of choice', Journal of Organizational Change Management, 21 (6), 721-42.

Ibarra, Herminia (1999), 'Provisional Selves: Experimenting with Image and Identity in Professional Adaptation', Administrative Science Quarterly, 44, 764-91.

Kogan, M (2000), 'Higher education communities and academic identity', Higher Education Quarterly, 54 (3), 207-16.

Kosmala, Katarzyna and Herrbach, Olivier (2006), 'The ambivalence of professional identity: On cynicism and jouissance in audit firms', Human Relations, 59 (10), 1393-428.

Miron-Spektor, Ella, et al. (2017), 'Microfoundations of Organizational Paradox: The Problem Is How We Think About the Problem', Academy of Management Journal, amj.2016.0594.

O’Connor, Kate Eliza (2008), '“You choose to care": Teachers, emotions and professional identity', Teaching and Teacher Education, 24 (1), 117-26.

Pratt, Michael G, Rockmann, Kevin W, and Kaufmann, Jeffrey B (2006), 'Constructing Professional Identity: The Role of Work and Identity Learning Cycles in the Customization of Identity among Medical Residents', The Academy of Management Journal, 49 (2), 235-62.

Provan, D. J., Dekker, S. W. A., and Rae, A, J. (2017), 'Bureaucracy, Influence and Beliefs: A literature review of the factors shaping the role of a safety professional', Safety Science, 98, 98112.

Pryor, P (2014), 'Towards an understanding of the strategic influence of the OHS professional', (Federation University).

Pryor, P, Hale, A, and Hudson, D (2015), 'The OHS Professional: A framework for practice Role, knowledge and skills. International Network of Safety and Health Practitioner Organisations', (Park Ridge, IL, USA.: INSHPO).

Reynolds, C (1996), 'Cultural scripts for teachers: identities and their relation to workplace landscapes', in M Kompf, et al. (eds.), Changing research and practice: teachers' professionalism, identities and knowledge (London: Falmer), 69-77. 
Schad, Jonathan, et al. (2016), 'Paradox Research in Management Science: Looking Back to Move Forward', The Academy of Management Annals, 10 (1), 5-64.

Schein, Edgar (1978), Career Dynamics: Matching Individual and Organizational Needs (Reading, MA: Addison-Wesley).

Scott, W. R. (2008), 'Lords of the Dance: Professionals as Institutional Agents', Organization Studies, 29 (2), 219-38.

Snook, S., Nohria, N., and Khurana, R. (eds.) (2011), The handbook for teaching leadership: Knowing, doing, and being (Sage).

Sugrue, C (1997), 'Student teachers' lay theories and teaching identities: their implications for professional development', European Journal of Teacher Education, 20 (3), 213-25.

Swuste, Paul, et al. (2014), 'Occupational safety theories, models and metaphors in the three decades since World War II, in the United States, Britain and the Netherlands: A literature review', Safety Science, 62, 16-27.

Symon, Gillian and Cassell, Catherine (2012), Qualitative Organizational Research: Core methods and current challenges (Sage Publications).

Wackerhausen, S. (2009), 'Collaboration, professional identity and reflection across boundaries', $J$ Interprof Care, 23 (5), 455-73.

Walsh, K and Gordon, J. R (2008), 'Creating an individual work identity', Human Resource Management Review, 18 (1), 46-61.

Walters, Doug (1999), 'Safety Officers: Are they police or are they psychologists', Chemical Health and Safety, (January/February), 36.

Webb, Stephen A (2015), 'Professional identity and social work', 5th International Conference on Sociology and Social Work.

Williams, Judy (2010), 'Constructing a new professional identity: Career change into teaching', Teaching and Teacher Education, 26 (3), 639-47. 
Woods, D. D. (2006), 'How to design a safety organization: Test case for resilience engineering', in E. Hollnagel, D. D. Woods, and Nancy Leveson (eds.), Resilience engineering: Concepts and precepts (Surrey: Ashgate), 315-25.

Yin, R. K. (2017), Case study research and applications: Design and methods (Sage publications). 